\title{
Utility of esophageal Doppler as a minimally inva- sive hemodynamic monitor: a review
}

\author{
[Revue de l'utilité du Doppler asophagien comme moniteur hémodynamique \\ à effraction minimale]
}

Kevin B. Laupland MD FRCPC, ${ }^{*}$ Colin J. Bands MB CHB FRCPC $†$

Purpose: The current bedside "gold standard" for cardiac output (CO) monitoring is thermodilution using a pulmonary artery catheter (PAC) but there is a number of risks associated with its use. The primary objective of this review was to evaluate the utility of esophageal Doppler (ED) as a minimally invasive monitor of CO.

Source: Medline literature search from 1966 to 2001 with citation review for studies comparing ED to PAC thermodilution for $\mathrm{CO}$ in perioperative and critically ill patients.

Principal findings: Twenty-five publications were identifed comparing ED and PAC measurement of $\mathrm{CO}$ in a broad range of patients. There was a good overall correlation between $\mathrm{CO}$ determined by ED and thermodilution ( $n=18$ studies, median $\mathrm{R}=$ 0.89 , range 0.52 to 0.98 ) and minimal bias $(n=13$, median -0.01 , range 1.38 to $2 \mathrm{~L} \cdot \mathrm{min}^{-1}$ ). The precision of ED was only fair overall as assessed by limits of agreement. The ED technique was found to be responsive in detecting changes in thermodilution $\mathrm{CO}$ and was reliable demonstrating both low intra- and inter-observer variation. ED was reportedly easy to insert after minimal training and was safe, with no significant complications identified.

Conclusion: ED is a practical, reliable, and valid device for measuring $\mathrm{CO}$ in perioperative and critically ill patients. Further studies with larger numbers of patients are needed to determine if the limited precision observed is inherent to the technique, the diagnoses of patients studied, or the small sample sizes.

Objectif : La thermodilution avec un cathéter artériel pulmonaire (CAP) représente la référence actuelle en monitorage de chevet du débit cardiaque (DC), mais elle comporte certains risques. L'objectif principal de la présente revue était d'évaluer l'utilité du Doppler œesophagien (DO) comme moniteur du DC à effraction minimale.
Source : Nous avons procédé à une recherche dans Medline, pour la période de 1966 à 200I, et à une revue des citations pour les études comparant l'usage périopératoire du DO et de la thermodilution avec CAP pour le DC chez des patients gravement malades.

Constatations principales : Vingt-cing articles traitaient de la comparaison des mesures du DC avec DO et CAP chez une grande diversité de patients. Une bonne corrélation globale a été notée entre le DC déterminé par le DO et la thermodilution ( $n=18$ études, $R$ médian $=0,89$, étendue de 0,52 à 0,98$)$ et biais minimal $(n=13$, médiane $-0,01$, étendue de 1,38 à $2 \mathrm{~L} \cdot \mathrm{min}^{-1}$ ). La précision du DO n'a été que bonne dans l'ensemble comme l'ont montré les limites de la concordance. La technique du DO a été trouvée efficace, car elle détecte les modifications du DC noté par thermodilution, et fiable, puisqu'elle peut démontrer une faible variation intra-observateur et interobservateur. Les articles révèlent que le DO est facile à insérer, ne requérant qu'une formation minimale, et sans risque, ne présentant pas de complications significatives connues.

Conclusion : Le DO est un appareil de mesure périopératoire du DC pratique, fiable et valide pour des patients gravement malades. D'autres études auprès d'un plus grand nombre de patients demeurent nécessaires pour déterminer si la précision limitée qui a été observée est inhérente à la technique, aux diagnostics des patients étudiés ou aux échantillonnages de faible effectif.

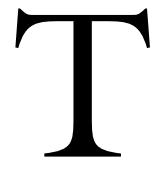

HE use of pulmonary artery catheters (PAC) for hemodynamic monitoring of perioperative and critically ill patients has become increasingly criticized. ${ }^{1}$ Since the introduction of the flow-directed balloon-tipped PAC three decades ago by Swan et al. there has been an explosion in its use. ${ }^{2}$ Despite concerns regarding its

From the Departments of Medicine, ${ }^{*}$ Critical Care, ${ }^{*} \dagger$ and Anesthesia, $\dagger$ Peter Lougheed Centre and the University of Calgary, Calgary, Alberta, Canada.

Address correspondence to: Dr. Colin J. Bands, Department of Anesthesia and Critical Care, Peter Lougheed Centre, 3500, $26^{\text {th }}$ Avenue N.E., Calgary, Alberta T1Y 6J4, Canada. Phone: 403-291-8315; Fax: 403-291-1491; E-mail: colin.bands@calgaryhealthregion.ca

Dr. Laupland was supported by the 2000 Bayer Healthcare/Canadian Institutes of Health Research/Canadian Infectious Diseases Society Research Fellowship and a clinical fellowship award from the Alberta Heritage Foundation for Medical Research.

Accepted for publication September 27, 2001.

Revision accepted January 16, 2002. 
safety and lack of empiric evidence for benefit, it has become a standard of care for managing high-risk perioperative and critically ill intensive care unit (ICU) patients in many centres. In the 1990's a number of non-randomized cohort and case-control studies associating the use of PAC with increased mortality were published with increasing concern raised about its widespread use. ${ }^{1,3,4}$

Sandham and colleagues on behalf of the Canadian Critical Care Clinical Trials Group recently reported on a randomized controlled trial of PAC use in 1994 high-risk geriatric surgical patients. ${ }^{5}$ They found no difference in the mortality rate $(7.8 \%$ PAC os $7.7 \%$ control) or length of hospitalization among patients treated with the aid of a PAC as compared to those managed without this device. However, patients randomized to PAC use showed a trend toward less renal impairment but suffered a significantly higher rate of procedural complications and pulmonary emboli. Although the results of this trial must be generalized cautiously to all high-risk perioperative and critically ill patients, this trial provides good evidence that PACs do not inherently increase mortality. However, it is not clear whether the potential advantages of less organ dysfunction and improved diagnostic certainty with PAC outweigh the significantly increased complications associated with its use.

Non-invasive or minimally invasive hemodynamic monitoring techniques may provide an alternative to the use of PAC. However, to be adopted, these techniques, at a minimum, need to demonstrate that they are safe and provide accurate hemodynamic information. A number of non-invasive or minimally invasive methods have been proposed and include esophageal Doppler (ED), transesophageal echocardiography, arterial waveform analysis, thoracic impedance, and modified Fick techniques. ${ }^{6-8}$ ED is well suited to the perioperative or ICU environment because it is a relatively simple technique that does not require specialized training or complex equipment. The primary objective of this report was to perform a semi-structured, comprehensive review of the utility of ED as a minimally invasive measure of cardiac output $(\mathrm{CO})$ in perioperative and critically ill adult patients. Since many critical care physicians and anesthesiologists may not be familiar with this technique, a brief review of theoretical and practical aspects of ED and its use as a cardiac preload measure is also presented.

\section{ED: theoretical considerations}

ED was first proposed as a minimally invasive hemodynamic measure in the 1970's and it has undergone significant technological advancement and clinical evaluation since..$^{9}{ }^{10}$ Initially, suprasternal transthoracic ultrasound/Doppler probes were used for determining $\mathrm{CO}$ but they were not widely adopted because probe position instability limited their use for repeated measures over extended periods of time. ${ }^{11}$ Esophageal probes were recognized to have two significant advantages over suprasternal probes. The first was that the smooth muscle tone of the esophagus is a natural means of maintaining the probe in position for repeated measures. The second was that the esophagus is in close anatomical proximity to the aorta so that signal interference from bone, soft tissue, and lung is minimized. Over the past three decades ED has evolved from an experimental technique to a relatively simple bedside procedure with the latest models incorporating both Doppler and echo-ultrasound in a single probe.

Determination of CO using ED is based on the following principles. ${ }^{12} \mathrm{~A}$ Doppler flow probe is used to directly measure flow velocity $\left(\mathrm{V}_{\mathrm{f}}\right)$. The cross sectional area of the aorta $\left(\mathrm{CSA}_{\mathrm{a}}\right)$ is then determined either by ultrasonic measurement or estimated using published nomograms. Aortic blood flow (ABF) is then calculated based on the product of $\mathrm{V}_{\mathrm{f}}$ and $\mathrm{CSA}_{\mathrm{a}}$. Because the ED probe measures ABF in the descending aorta, the measured $\mathrm{ABF}$ is always less than $\mathrm{CO}$ as a result of blood flow to aortic arch branches. Although it varies among patients and disease states, $\mathrm{ABF}$ is typically $70 \%$ of CO. ${ }^{12}$ Therefore, ED probes directly measure $\mathrm{ABF}$ but only estimate $\mathrm{CO}$.

There are a number of considerations regarding the accuracy of ED for estimating CO. First, turbulence arising from thoracic aortic aneurysms, intra-aortic balloon pumps, and aortic valve disease may affect the $\mathrm{V}_{\mathrm{f}}$ profile and lead to invalid results. However, this is a theoretical concern that has not been adequately studied. Second, the assumption of a constant proportion of blood flow to the descending aorta may not be valid such as in the setting of aortic coarctation, aortic cross-clamp, acute bleeding, or pregnancy. ${ }^{13,14}$ Finally, the CSA may vary considerably between patients and within the same patient in different disease states. Some ED models estimate CSA asing nomograms based on patient gender, age, and body surface area or use a single transthoracic ultrasonic measure at the start of the study. In the former case, significant error in the actual aortic diameter may occur as a result of biological variation and in both cases error may arise from changing states of hydration, stress, vasoactive medication use, or from application of an aortic crossclamp. ${ }^{11,15,16}$ In an attempt to minimize this error, an echo-ED model that contains both a Doppler and ultrasound (M-mode) probe has been developed. ${ }^{12}$ 
With the echo-ED, real-time measurements of $\mathrm{V}_{\mathrm{f}}$ and $\mathrm{CSA}_{\mathrm{a}}$ are made and continuously measured ABF is displayed.

\section{ED: practical considerations}

\section{Probe placement}

The ED probe is placed via the oral or nasal route and may be left in situ for days to weeks. ${ }^{17}$ The ideal probe tip location is at the level between the fifth and sixth thoracic vertebrae because at that level the aorta is adjacent and parallel to the esophagus. ${ }^{18}$ This location is achieved by superficially landmarking the distance to the third sternocostal junction anteriorly and is approximately 30 to $40 \mathrm{~cm}$ in the average adult. After insertion, the ED probe is then rotated on its axis to achieve an optimal signal prior to taking measurements. Contraindications to ED use include known esophageal anatomical abnormalities such as malformations, tumours, strictures or varices, recent esophageal or upper airway surgery, or acute esophagitis. Because of the mild discomfort associated with placing the probe (comparable to insertion of a nasogastric or orogastric drainage tube) and maintaining it in fixed position, patients monitored with an ED require adequate sedation.

\section{Safety and ease of use}

ED appears to be associated with few complications and minimal training is required to insert and achieve an adequate signal in most patients. Although not formally timed in studies, ED has been reported to typically take less than five minutes to place and obtain a clear signal. ${ }^{17,19,20}$ Two studies have formally evaluated the role of experience on the quality of results and found that approximately ten to 12 patients were required for an operator to develop consistent efficiency and accura$\mathrm{cy}^{21,22}$ No major adverse events related to the use of ED were reported in any of the literature included in this review. Furthermore, one author has anecdotally reported no significant complications with his use of ED in more than 500 patients. ${ }^{17}$

\section{$\mathrm{ED}$ as a valid measure of $\mathrm{CO}$ \\ Search strategy}

CO determination by thermodilution using a PAC is the current bedside "gold standard" method and has been shown to be comparable to other valid measures including the Fick and dye dilution techniques. ${ }^{23}$ Since PAC thermodilution cardiac output $\left(\mathrm{CO}_{\mathrm{TD}}\right)$ is the most widely used standard, a Medline search from 1966 to February 2001 was conducted to identify published studies comparing $\mathrm{CO}_{\mathrm{TD}}$ and $\mathrm{ED} \mathrm{CO}$ $\left(\mathrm{CO}_{\mathrm{ED}}\right)$ or $\mathrm{ABF}$ in perioperative and intensive care patients. Search terms included PAC, Swan Ganz catheterization, ED, and Doppler echocardiography. Studies were limited to English language, human, and age $>12$ yr. Abstracts were screened and full-length articles were retrieved for all relevant studies. Review articles and bibliographies of identified studies were searched in an attempt to identify other studies missed by the Medline search strategy.

\section{Measures of agreement}

In this review the parameters of Bland and Altman were chosen in preference to the product-moment correlation coefficient ( $R$ ) to assess agreement between $\mathrm{CO}_{\mathrm{TD}}$ and $\mathrm{CO}_{\mathrm{ED}}$ or $\mathrm{ABF}{ }^{24}$ The productmoment correlation coefficient is merely a measure of the degree of linear association between the two methods and is a poor measure of agreement or the degree to which the two techniques measure the same absolute value. In Bland-Altman analysis, the difference between the two measures $\left(\mathrm{CO}_{\mathrm{TD}}-\mathrm{CO}_{\mathrm{ED}}\right)$ is plotted against their mean $\left[1 / 2\left(\mathrm{CO}_{\mathrm{TD}}+\mathrm{CO}_{\mathrm{ED}}\right)\right]$. The mean difference or "bias" is a measure of how well the two techniques agree on average. ${ }^{25} \mathrm{~A}$ measure of precision or range of agreement for a given individual is expressed as the 95\% "limits of agreement". This is calculated as the bias \pm two standard deviations of the differences. Practically, if 95\% limits of agreement (LOA) are within clinically acceptable limits the two techniques may be used interchangeably. ${ }^{24}$

\section{Identified studies}

A total of 25 full-length articles and abstracts were identified that fulfilled the search criteria and are shown in the Table. Nineteen reports evaluated $\mathrm{ED}^{13,14,21,22,26-39}$ and $\operatorname{six}^{16,20,40-43}$ assessed echo-ED $\mathrm{CO}_{\mathrm{ED}} / \mathrm{ABF}$ vs PAC $\mathrm{CO}_{\mathrm{TD}}$ respectively. However, one data set was published twice, ${ }^{42,43}$ and one abstract that was more than five years old was excluded from review based on journal policy. ${ }^{44}$ No studies were identified that directly compared ED $\mathrm{CO} / \mathrm{ABF}$ with echo-ED CO/ABF. The identified studies varied considerably in patient population and in quality (Table). Twelve studies were from Europe, nine from the United States, one from Australia, and one from South Africa. There was a broad range of patients enrolled including perioperative (cardiac, aortic reconstructive, and general surgery) and medical and surgical ICU patients. The studies were generally small with a median of 20 (range 9 to 60) patients. It is not practical to report a detailed critical appraisal of each of the study methodologies in this review. However, despite its importance to the validity of their results, it is notable that only a minority of the studies described an adequate blinding process. ${ }^{13,26,28,29,39}$ Furthermore, a number of 
TABLE Summary of studies for ED CO

\begin{tabular}{|c|c|c|c|c|c|}
\hline $\begin{array}{l}\text { Study population } \\
\text { (year) }\end{array}$ & Modalities compared & $\begin{array}{l}\text { Number of patients } \\
\text { (paired measurements) }\end{array}$ & Results & Limitations & Reference \\
\hline $\begin{array}{l}\text { ICU, Lyon, France } \\
\text { (1985) }\end{array}$ & $\begin{array}{l}\text { Echo esophageal } \\
\text { Doppler (ED) vs } \\
\text { thermodilution } \\
\text { cardiac output } \\
\left(\mathrm{CO}_{\mathrm{TD}}\right)\end{array}$ & $21(300)$ & $\mathrm{R}=0.98$ & $\begin{array}{l}\text { Not blinded, no } \\
\text { Bland-Altman (BA) } \\
\text { analysis }\end{array}$ & $(42,43)$ \\
\hline $\begin{array}{l}\text { Cardiac surgery, } \\
\text { Boston, USA } \\
1986\end{array}$ & $\begin{array}{l}\text { ED (Ultracom, } \\
\text { Lawrence Medical } \\
\text { Systems, Camarillo } \\
\text { USA) vs } \mathrm{CO}_{\mathrm{TD}}\end{array}$ & $16(372)$ & $\mathrm{R}=0.92$ & $\begin{array}{l}\text { Not blinded, no } \\
\text { BA analysis, small } \\
\text { study }\end{array}$ & $(32)$ \\
\hline $\begin{array}{l}\text { Elective surgery, } \\
\text { Seattle, USA (1987) }\end{array}$ & $\begin{array}{l}\mathrm{ED}(\text { Ultracom }) v s \\
\mathrm{CO}_{\mathrm{TD}}\end{array}$ & $23(420)$ & $\begin{array}{l}\mathrm{R}=0.67 \text { overall, after } \\
\text { the first ten patients } \\
\mathrm{R}=0.85 . \text { Bias }(\text { limits } \\
\text { of agreement, LOA) } \\
-0.16(-0.97,0.65) \\
\mathrm{L} \cdot \mathrm{min}^{-1}\end{array}$ & $\begin{array}{l}\text { Not blinded, results } \\
\text { statistical analysis } \\
\text { not well described }\end{array}$ & $(22)$ \\
\hline $\begin{array}{l}\text { Cardiovascular } \\
\text { surgery, Stanford, } \\
\text { USA (1988) }\end{array}$ & $\begin{array}{l}\mathrm{ED} \text { (Lawrence } 3000 \text {, } \\
\text { Lawrence Medical } \\
\text { Systems) vs } \mathrm{CO}_{\mathrm{TD}}\end{array}$ & $9(25)$ & $\begin{array}{l}\mathrm{R}=0.68 \\
\text { Bias }-0.1 \mathrm{~L} \cdot \mathrm{min}^{-1}\end{array}$ & $\begin{array}{l}\text { Not blinded, small } \\
\text { study, LOA } \\
\text { reported inconsistently } \\
\text { in article }\end{array}$ & (35) \\
\hline $\begin{array}{l}\text { Surgical or ICU } \\
\text { patients, London } \\
\text { UK (1989) }\end{array}$ & $\begin{array}{l}\mathrm{ED} \text { (prototype) } v s \\
\mathrm{CO}_{\mathrm{TD}}\end{array}$ & $38(238)$ & $\begin{array}{l}\text { Percent bias (LOA) } \\
\text { for changes in } \mathrm{CO}_{\mathrm{TD}} \\
0.6 \%(-13.5 \%, 14.7 \%)\end{array}$ & $\begin{array}{l}\text { No R between } \\
\mathrm{CO}_{\mathrm{TD}} \text { and ED or } \\
\mathrm{BA} \text { analysis reported, } \\
\text { not blinded }\end{array}$ & $(36)$ \\
\hline $\begin{array}{l}\text { Elective surgery, } \\
\text { Los Angeles, USA } \\
(1989)\end{array}$ & $\begin{array}{l}\mathrm{ED}(\text { Ultracom }) v s \\
\mathrm{CO}_{\mathrm{TD}}\end{array}$ & $14(246)$ & $\begin{array}{l}\mathrm{R}=0.75 \\
\text { Bias }-1.38 \mathrm{~L} \cdot \mathrm{min}^{-1}\end{array}$ & $\begin{array}{l}\text { Not blinded, } \\
\text { small study }\end{array}$ & $(30)$ \\
\hline $\begin{array}{l}\text { Postcardiac } \\
\text { surgery ICU, } \\
\text { Zurich, Switzerland } \\
\text { (1990) }\end{array}$ & $\begin{array}{l}\text { ED (Accucom I, } \\
\text { Datascope Corp. } \\
\text { Paramus, USA) vs } \\
\mathrm{CO}_{\mathrm{TD}}\end{array}$ & $23(96)$ & $\mathrm{R}=0.55$ & $\begin{array}{l}\text { Not blinded, } \\
\text { no BA analysis }\end{array}$ & $(37)$ \\
\hline $\begin{array}{l}\text { Noncardiac surgery, } \\
\text { New Haven, USA }\end{array}$ & $\begin{array}{l}\mathrm{ED} \text { (Accucom I and } \\
\text { II) } p s \mathrm{CO}_{\mathrm{TD}}\end{array}$ & $43(923)$ & $\begin{array}{l}\text { Accucom I: } \mathrm{R}=0.72 \\
\text { bias }(\mathrm{LOA})-0.4 \\
(-2.9,2) ; \text { Accucom II } \\
\mathrm{R}=0.91, \text { bias }(\mathrm{LOA}) \\
-0.2(-1.6,1.2) \mathrm{L} \cdot \mathrm{min}^{-1}\end{array}$ & $\begin{array}{l}\text { Exact values for } \\
\text { BA analysis not } \\
\text { reported (estimated } \\
\text { from graphs), not } \\
\text { blinded }\end{array}$ & $(33)$ \\
\hline $\begin{array}{l}\text { Cardiac surgery, } \\
\text { Sydney, Australia } \\
\text { (1991) }\end{array}$ & $\begin{array}{l}\mathrm{ED} \text { (Lawrence 3000) } \\
\text { vs } \mathrm{CO}_{\mathrm{TD}}\end{array}$ & $11(106)$ & $\begin{array}{l}\text { Bias }-1.0 \mathrm{LOA}(-4.6 \text {, } \\
\text { 2.6) } \mathrm{L} \cdot \mathrm{min}^{-1} \text {. }\end{array}$ & $\begin{array}{l}\text { Small study, not } \\
\text { blinded }\end{array}$ & (38) \\
\hline $\begin{array}{l}\text { Abdominal aortic } \\
\text { surgery, New } \\
\text { Haven, USA }\end{array}$ & $\begin{array}{l}\mathrm{ED}(\text { Accucom II }) \\
\text { vs } \mathrm{CO}_{\mathrm{TD}}\end{array}$ & $39(489)$ & $\begin{array}{l}\text { Baseline } \mathrm{R}=0.94, \mathrm{X}- \\
\text { clamp } \mathrm{R}=0.72, \\
\text { postclamp } \mathrm{R}=0.88 . \\
\text { Approx. Bias (LOA) } \\
\text { baseline }-0.3(-1.7, \\
\text { 1.1), X-clamp } 0.7(-1.9 \text {, } \\
3.3) \text { postclamp }-0.1 \\
(-1.6,1.4) \mathrm{L} \cdot \mathrm{min}^{-1} \text {. }\end{array}$ & $\begin{array}{l}\text { Exact values for } \\
\text { BA analysis not } \\
\text { reported (estimated } \\
\text { from graphs) }\end{array}$ & (13) \\
\hline $\begin{array}{l}\text { Postop cardiac } \\
\text { surgery patients } \\
\text { Zurich, Switzerland } \\
\text { (1993) }\end{array}$ & $\begin{array}{l}\mathrm{ED}(\text { Accucom II }) v s \\
\mathrm{CO}_{\mathrm{TD}}\end{array}$ & $16(140)$ & $\begin{array}{l}\mathrm{R}=0.52, \text { bias }(\mathrm{LOA}) \\
-0.37(-3.8,3.0) \\
\mathrm{L} \cdot \mathrm{min}^{-1} .\end{array}$ & $\begin{array}{l}\text { Not blinded, small } \\
\text { study }\end{array}$ & $(34)$ \\
\hline
\end{tabular}


TABLE continued

\begin{tabular}{|c|c|c|c|c|c|}
\hline $\begin{array}{l}\text { Study population } \\
\text { (year) }\end{array}$ & Modalities compared & $\begin{array}{l}\text { Number of patients } \\
\text { (paired measurements) }\end{array}$ & Results & Limitations & Reference \\
\hline $\begin{array}{l}\text { Cardiac surgery, } \\
\text { Belfast, Northern } \\
\text { Ireland (1997) }\end{array}$ & $\begin{array}{l}\mathrm{ED}(\mathrm{ODM} \mathrm{II} \\
\text { Doptek) vs } \\
\text { continuous } \mathrm{CO}_{\mathrm{TD}}\end{array}$ & $\begin{array}{l}11 \text { Group I } \\
\text { (probe not } \\
\text { readjusted) } 5 \\
\text { Group II (probe } \\
\text { readjusted) }\end{array}$ & $\begin{array}{l}\text { Bias }(\mathrm{LOA}) \text { for } \\
\text { Group I }=0.8(-2.2, \\
3.8) \text { and Group II }= \\
0.14(-0.58,0.85) \\
\mathrm{L} \cdot \mathrm{min}^{-1}\end{array}$ & Small study & $(29)$ \\
\hline $\begin{array}{l}\text { ICU patients, } \\
\text { Nimes, France }\end{array}$ & $\begin{array}{l}\mathrm{ED}(\mathrm{ODM} \mathrm{I}) v s \\
\mathrm{CO}_{\mathrm{TD}}\end{array}$ & $\begin{array}{l}11(107) \text { training, } \\
49(320) \text { evaluation }\end{array}$ & $\begin{array}{l}\text { Training and evaluation } \\
\mathrm{R}=0.53 \text { and } \\
\mathrm{R}=0.89, \text { bias }(\mathrm{LOA}) \\
1.2(-2.0,4.4) \text { and } \\
0.1(-2.1,2.3) \\
\mathrm{L} \cdot \mathrm{min}^{-1} \text { respectively }\end{array}$ & $\begin{array}{l}\text { Unclear if adequate } \\
\text { blinding in evaluation } \\
\text { phase }\end{array}$ & $(21)$ \\
\hline $\begin{array}{l}\text { Medical ICU, } \\
\text { Paris, France } \\
\text { Paris, France) vs } \mathrm{CO}_{\mathrm{TD}}\end{array}$ & $\begin{array}{l}\text { Echo-ED (Dynemo- } \\
\text { 3000, Sometec Inc., }\end{array}$ & $20(80)$ & $\mathrm{R}=0.80$ & $\begin{array}{l}\text { Not blinded, } \\
\text { no BA analysis }\end{array}$ & $(41)$ \\
\hline $\begin{array}{l}\text { Medical ICU, } \\
\text { Nice, France } \\
(1998)\end{array}$ & $\begin{array}{l}\text { Echo-ED (Dynemo- } \\
3000) \text { vs } \mathrm{CO}_{\mathrm{TD}}\end{array}$ & $22(60)$ & $\mathrm{R}=0.92$ & $\begin{array}{l}\text { BA analysis } \\
\text { not reported }\end{array}$ & (16) \\
\hline $\begin{array}{l}3 \text { ICUs in Paris, } \\
\text { France (1998) }\end{array}$ & $\mathrm{ED}(\mathrm{ODMI}) v s \mathrm{CO}_{\mathrm{TD}}$ & $46(136)$ & $\begin{array}{l}\mathrm{R}=0.95, \text { bias }(\mathrm{LOA}) \\
0.24(-1.56,2.04) \\
\mathrm{L} \cdot \mathrm{min}^{-1}\end{array}$ & & (39) \\
\hline $\begin{array}{l}\text { Cardiac or } \\
\text { abdominal surgery, } \\
\text { Stuttgart, Germany } \\
(1998)\end{array}$ & $\begin{array}{l}\text { Echo-ED (Dynemo } \\
3000) \text { vs } \mathrm{CO}_{\mathrm{TD}}\end{array}$ & $48(171)$ & $\mathrm{R}=0.90$ & $\begin{array}{l}\text { No BA analysis, } \\
\text { not blinded, abstract } \\
\text { publication }\end{array}$ & $(20)$ \\
\hline $\begin{array}{l}\text { Surgical ICU } \\
\text { Detroit, USA } \\
(1998)\end{array}$ & $\begin{array}{l}\mathrm{ED} \text { (EDM, Deltex } \\
\text { Medical Inc.) vs } \mathrm{CO}_{\mathrm{TD}}\end{array}$ & 10 & $\mathrm{R}=0.92$ & $\begin{array}{l}\text { No BA, analysis, } \\
\text { not blinded, abstract } \\
\text { publication, small } \\
\text { study }\end{array}$ & $(27)$ \\
\hline $\begin{array}{l}\text { ICU, Bobigny, } \\
\text { France (1999) } \\
3 \text { Surgical ICUs } \\
\text { in New Orlean's } \\
\text { USA (1999) }\end{array}$ & $\begin{array}{l}\mathrm{ED}(\mathrm{ODM} \mathrm{II}) v s \\
\text { continuous } \mathrm{CO}_{\mathrm{TD}} \\
\mathrm{ED}(\text { Deltex }) v s \\
\mathrm{CO}_{\mathrm{TD}}\end{array}$ & $\begin{array}{l}10(145) \\
14(118)\end{array}$ & $\begin{array}{l}\text { Bias (LOA) }-0.01 \\
(-0.97,0.96) \mathrm{L} \cdot \mathrm{min}^{-1} \\
\mathrm{R}=0.77\end{array}$ & $\begin{array}{l}\text { Small study } \\
\text { Not blinded, } \\
\text { no BA analysis, } \\
\text { small study }\end{array}$ & $\begin{array}{l}(26) \\
(31)\end{array}$ \\
\hline $\begin{array}{l}\text { Off pump cardiac } \\
\text { surgery, Stuttgart, } \\
\text { Germany (1999) }\end{array}$ & $\begin{array}{l}\text { Echo-ED (Dynemo } \\
3000) \text { ps } \mathrm{CO}_{\mathrm{TD}}\end{array}$ & $10(50)$ & $\begin{array}{l}\mathrm{R}=0.89 \\
\text { Bias (LOA) } 0.77 \\
(-0.49,2.03) \mathrm{L} \cdot \mathrm{min}^{-1}\end{array}$ & $\begin{array}{l}\text { Not blinded, } \\
\text { abstract publication, } \\
\text { small study }\end{array}$ & $(40)$ \\
\hline $\begin{array}{l}\text { Preeclampsia, Cape } \\
\text { Town, South Africa }\end{array}$ & $\mathrm{ED} v s \mathrm{CO}_{\mathrm{TD}}$ & 17 & $\begin{array}{l}\text { Bias (LOA) } 2.0 \\
(-1.0,5.0) \mathrm{L} \cdot \mathrm{min}^{-1}\end{array}$ & $\begin{array}{l}\text { Not blinded, type } \\
\text { of ED and ABF } \\
\text { correction factor } \\
\text { not specified, } \\
\text { small study }\end{array}$ & (14) \\
\hline $\begin{array}{l}\text { Elective cardiac } \\
\text { surgery, Dallas, } \\
\text { USA (2000) }\end{array}$ & $\begin{array}{l}\mathrm{ED} \text { (Deltex) vs } \mathrm{CO}_{\mathrm{TD}} \\
\text { vs direct aortic flow } \\
\text { probe }\end{array}$ & $34(160)$ & $\begin{array}{l}\mathrm{R}=0.77 \text { for } \mathrm{ED}-\mathrm{CO} \\
\text { vs flow probe } \\
\text { comparable to } \mathrm{CO}_{\mathrm{TD}}\end{array}$ & $\begin{array}{l}\text { Did not report } \\
\text { correlation or } \\
\text { agreement directly } \\
\text { with } \mathrm{CO}_{\mathrm{TD}}\end{array}$ & $(28)$ \\
\hline
\end{tabular}

$\mathrm{ICU}=$ intensive care unit; $\mathrm{ABF}=$ aortic blood flow. 
the studies were limited because they only reported correlation coefficients and did not perform Bland-Altman analysis of their results. ${ }^{24}$

$C O_{E D}$ vs $C O_{T D}$

In general, the studies showed good correlation between the $\mathrm{ED}$ derived $\mathrm{ABF}$ or $\mathrm{CO}$ and $\mathrm{CO}_{\mathrm{TD}}$. In the 18 studies that reported the correlation coefficient, the median was 0.89 (range 0.52 to 0.98 ). There was a tendency for a higher correlation to be observed with the newer generations of ED and echo-ED (Table). Among the 13 studies that reported a measure of bias, the median was -0.01 (range -1.38 to 2 ) $\mathrm{L} \cdot \mathrm{min}^{-1}$. It is not possible to estimate composite LOA without the raw data from each of the studies. Boulnois and Pechoux ${ }^{12}$ pooled three studies ${ }^{16,20,41}$ of echo-ED and found among 90 (311 matched measurements) patients a correlation coefficient of 0.89 , bias of $0.06 \mathrm{~L} \cdot \mathrm{min}^{-1}$, and LOA -2.21 to $2.33 \mathrm{~L} \cdot \mathrm{min}^{-1}$.

\section{Responsiveness}

Five studies specifically quantified ED's ability to detect changes in $\mathrm{CO}_{\mathrm{TD}}$. Studies typically defined a significant change in $\mathrm{CO}_{\mathrm{TD}}$ as at least a $12-15 \%$ difference from baseline as per Stetz et al. ${ }^{23}$ Valtier et al. found good agreement between changes in $\mathrm{CO}_{\mathrm{TD}}$ and $\mathrm{CO}_{\mathrm{ED}} \mathrm{R}=$ 0.9 , bias $0 \mathrm{~L} \cdot \mathrm{min}^{-1}$, LOA -1.7 to $\left.1.7 \mathrm{~L} \cdot \mathrm{min}^{-1}\right) .{ }^{39}$ Cariou and colleagues calculated a sensitivity of $75 \%$ and specificity of $95 \%$ for echo-ED to detect a $13 \%$ change in $\mathrm{CO}_{\mathrm{TD}}$ in medical ICU patients. ${ }^{41}$ In patients undergoing aortic reconstructive surgery, Perrino found that ED detected changes of $15 \% \mathrm{CO}_{\mathrm{TD}}$ with a sensitivity of $89 \%$ without and $79 \%$ during cross-clamping of the aorta. ${ }^{13}$ Two studies calculated percent bias (LOA) for changes in $\mathrm{CO}_{\mathrm{TD}}$ of $0.6 \%(-13.5 \%, 14.7 \%)$ and $-0.66 \%$ $(-20.1 \%, 18.8 \%))^{34,36}$ Penney et al. found that $\mathrm{CO}_{\mathrm{ED}}$ correctly tracked $\mathrm{CO}_{\mathrm{TD}}$ changes in 13 of 16 women with pre-eclampsia but they did not quantify the magnitude. ${ }^{14}$ Kumar and colleagues reported similar results in 11 of 14 anesthetized surgical patients. ${ }^{30}$

\section{Reliability}

Six studies assessed the reproducibility of ED both between (inter-observer) and within (intra-observer) operators. ${ }^{16,30,32,36,39,43}$ Inter-observer variability was assessed with echo-ED in two studies with 11 and 22 patients that found differences with repeated measures in stable patients to be $0.75 \%$ and $3.3 \%$ respectively between two operators blinded to each other's findings. ${ }^{16,43}$ Intra-observer variability as assessed by calculating the coefficient of variation in four studies was $8 \%$, $5.7 \%, 3.8 \%$, and $3.3 \%$ for ED as compared to $12 \%, 8.3 \%$, $6.2 \%$, and $4.6 \%$ for thermodilution respectively. ${ }^{16,32,36,39}$

\section{Applicability}

The proportion of patients for whom a successful insertion and signal was obtained was $97 \%$ among the 558 patients included in this review. This rate, however, refers to those patients that were enrolled in the studies and does not necessarily reflect the applicability rate of consecutive patients presenting to the operating room or ICU. Reasons cited for ED failure included interference from a nasogastric tube, lung disease and particularly adult respiratory distress syndrome requiring high levels of positive end-expiratory airway pressure, and poor signal quality or inability to maintain a stable signal for unspecified reasons. . $^{13,16,20,21,30,33,37}$

\section{ED for preload assessment}

Although CO is the most valuable hemodynamic parameter, assessment of ventricular filling is also believed to be important in management of perioperative and critically ill patients. Unlike the use of PAC thermodilution for $\mathrm{CO}$ determination, there is unfortunately no bedside gold standard for determining optimal ventricular filling. In the absence of a good measure, the pulmonary capillary wedge pressure (PCWP) using a PAC is commonly used. However, the PCWP is subject to a number of technical, disease related, and interpretation problems and its validity has not been proven in critically ill human beings. ${ }^{45,46} \mathrm{ED}$ waveform analysis has been increasingly evaluated as a method for determining optimum cardiac preload. A detailed description of ED $V_{f}$ waveform shape analysis is beyond the scope of this article, but it has been reviewed extensively by Singer. ${ }^{17}$ The key preload parameter of interest is the flow time, that is the time required from start of waveform upstroke to return to baseline. Since the flow time is heart rate dependent it is typically corrected $\left(\mathrm{FT}_{\mathrm{c}}\right)$ by dividing the flow time by the square root of the cycle time (normal range approximately 330 to $360 \mathrm{msec}$ ). ${ }^{17} \mathrm{Few}$ studies have attempted to evaluate the $\mathrm{FT}_{c}$ as a preload measure and are detailed in the following two paragraphs.

Singer and Bennett investigated $\mathrm{FT}_{\mathrm{c}}$ as a measure of ventricular filling by placing an ED and a PAC in 43 mechanically ventilated ICU and cardiothoracic surgery patients in London, UK ${ }^{47}$ After baseline measures, the patient's ventricular filling was manipulated either by increasing it with iv fluid loading if hypovolemic (PCWP $<8 \mathrm{mmHg}$ ) or by decreasing it with $i v$ nitrates if either normovolemic (PCWP $8-20 \mathrm{mmHg}$ ) and hypertensive or hypervolemic (PCWP > $20 \mathrm{mmHg}$ ). Patients who had decreased preload from intraoperative hemorrhage were also followed. They observed a matched increase in PCWP and $\mathrm{FT}_{\mathrm{c}}$ with fluid loading 
among all 18 patients with hypovolemia. Similarly, all normovolemic patients had a concordant decrease in PCWP and $\mathrm{FT}_{\mathrm{c}}$. However, while the PCWP decreased in all 12 hypervolemic patients, the $\mathrm{FT}_{c}$ increased initially in $11 / 12$ patients (reflecting optimal $\mathrm{CO}$ ) prior to decreasing. Thus, $\mathrm{FT}_{\mathrm{c}}$ appears to be a useful measure to direct optimal ventricular loading.

Two other studies have been undertaken to try to assess $\mathrm{FT}_{c}$ as a measure of ventricular filling. DiCorte $e t$ al. in a blinded fashion compared pulmonary artery diastolic $\left(\mathrm{PA}_{\mathrm{d}}\right)$ pressure and $\mathrm{FT}_{\mathrm{c}}$ by ED to end-diastolic short-axis area (EDA) as measured by transesophageal echocardiography in 20 patients undergoing coronary bypass surgery. ${ }^{28}$ They found a modest correlation between $\mathrm{FT}_{\mathrm{c}}$ and EDA $(\mathrm{R}=0.49)$ and a poor correlation with $\mathrm{PA}_{d}$ pressure and EDA $(\mathrm{R}=0.10)$. Although this provides some evidence that $\mathrm{FT}_{\mathrm{c}}$ may be a better measure of preload than $\mathrm{PA}_{\mathrm{d}}$ it is not a clinically relevant comparison because PCWP is virtually always used in preference to $\mathrm{PA}_{\mathrm{d}}$. Madan and colleagues conducted a study among 14 surgical ICU patients comparing ED with PAC. ${ }^{31}$ They found a better correlation between $\mathrm{FT}_{\mathrm{c}}(\mathrm{R}=0.52)$ and $\mathrm{CO}_{\mathrm{TD}}$ than with $\operatorname{PCWP}(\mathrm{R}=0.2)$ and $\mathrm{CO}_{\mathrm{TD}}$. Further study is needed to define the role of $\mathrm{FT}_{\mathrm{c}}$ based optimization of ventricular filling.

\section{ED driven protocols}

\section{Improved patient outcome?}

In assessing any new technology or treatment an important criteria for its adoption is whether it can be shown to decrease morbidity and/or mortality. Two studies have shown improved outcomes with the use of ED perioperatively. ${ }^{48,49}$ Sinclair et al. conducted a randomized controlled trial with 40 geriatric patients undergoing fractured hip repair under general anesthesia in London, UK. ${ }^{49}$ All patients had an ED inserted but were randomized to either an intraoperative volume optimization protocol (goal FT $_{c}>350 \mathrm{msec}$ and optimized stroke volume) vs usual care. Anesthesiologists were blinded to ED values but not to the iv volume administered. Protocol patients received significantly more fluid, had higher mean $\mathrm{FT}_{\mathrm{c}}$ and $\mathrm{CO}$ values, but had similar blood pressure and heart rates compared to controls intraoperatively. Protocol patients had significant reductions in the main outcome measures of median time to be declared fit for discharge of ten vs 15 days and length of hospitalization of 12 vs 20 days as compared to control respectively $(P<0.05$ for both $)$. An important potential limitation of this study is that protocol patients may have been recognized (unblinded) based on the increased amount of fluids given and possibly discharged earlier.
In the other study by Mythen et al., a prospective, randomized, open study was conducted with 60 elective cardiac surgery patients in London, UK. ${ }^{48}$ The control patients received usual care and the treatment patients were given repeated boluses of $6 \%$ hydroxyethyl starch to maximize stroke volume based on ED and central venous pressure. Compared to control, the treatment group had a lower incidence of gut hypoperfusion as measured by gastric intramucosal $\mathrm{pH}<$ 7.32 ( $7 \%$ vs $56 \%, P<0.001)$, less major complications (zero vs six patients, $P=0.01$ ), and shorter mean lengths of ICU (one vs 1.7 days, $P=0.023$ ) and overall hospital stay (6.4 vs 10.1 days, $P=0.011)$. The main limitation of this study is that it was not blinded and knowledge of the patients' treatment allocation may have influenced either management or ascertainment of outcome. Furthermore, as with the Sinclair study, the authors did not adequately describe a mechanism by which protocol patients would be able to be discharged earlier. Despite the limitations of these two studies, they are important contributions to the ED literature because they showed improvements in clinical outcomes with ED usage.

\section{Summary and conclusions}

$\mathrm{ED}$ is a minimally invasive technique that has a good safety profile, is easy to use, and requires only minimal training. When compared to the current bedside gold standard of bolus $\mathrm{CO}_{\mathrm{TD}}$ using a PAC in a broad range of perioperative and critically ill patients, ED was found to be reliable, responsive to changes, and have good agreement with low bias in the majority of studies. However, wide limits of agreement were observed with ED in several studies raising concerns about the precision of this technique. Further clinical investigation with larger numbers of varied patients is required to determine if the limited precision observed is inherent to the technique, related to patients' diagnoses, or is simply a function of the small study sample sizes used. It is unlikely that ED will replace PAC at present because of the concerns regarding limited precision and reduced applicability. However, use of ED may lead to a reduction of the number of patients undergoing invasive monitoring with its associated risks. Future clinical investigations will hopefully further define its role in optimization of ventricular filling and in improving the outcome of perioperative and critically ill patients.

\section{References}

1 Pulmonary Artery Catheter Consensus Conference Participants. Pulmonary artery catheter consensus conference: consensus statement. Crit Care Med 1997; 25 : 910-24. 
2 Swan HJC, Ganz W, Forrester J, Marcus H, Diamond $G$, Chonette D. Catheterization of the heart in man with use of a flow-directed balloon-tipped catheter. N Engl J Med 1970; 283: 447-51.

3 Connors AF Jr, Speroff T, Dawson NV, et al. The effectiveness of right heart catheterization in the initial care of critically ill patients. JAMA 1996; 276: 889-97.

4 Zion MM, Balkin J, Rosenmann D, et al. Use of pulmonary artery catheters in patients with acute myocardial infarction. Analysis of experience in 5,841 patients in the SPRINT registry. Chest 1990; 98: 1331-5.

5 Sandham JD, Hull RD, Brant R, and the Canadian Critical Care Clinical Trials Group Rationale. A randomized controlled trial of pulmonary artery catheter use in 1994 high-risk geriatric surgical patients. Am J Respir Crit Care Med 2001; 163: Al6 (abstract).

6 Singer M. Cardiac output in 1998. Heart 1998; 79: 425-8.

7 Newman DG, Callister $R$. The non-invasive assessment of stroke volume and cardiac output by impedance cardiography: a review. Aviat Space Environ Med 1999; 70: 780-9.

8 Troianos CA, Porembka DT. Assessment of left ventricular function and hemodynamics with transesophageal echocardiography. Crit Care Clin 1996; 12: 253-72.

9 Side C, Gosling R. Non-surgical assessment of cardiac function. Nature 1971; 232: 335-6.

10 Daigle RE, Miller CW, Histand MB, McLeod FD, Hokanson DE. Nontraumatic aortic blood flow sensing by use of using an ultrasonic esophageal probe. J Appl Physiol 1975; 38: 1153-60.

11 Huntsman LL, Stewart DK, Barnes SR, Franklin SB, Colocousis JS, Hessel EA. Noninvasive Doppler determination of cardiac output in man. Clinical validation. Circulation 1983; 67: 593-602.

12 Boulnois JG, Pechoux T. Non-invasive cardiac output monitoring by aortic blood flow measurement with the Dynemo 3000. J Clin Monit 2000; 16: 127-40.

13 Perrino AC Jr, Fleming J, LaMantia KR. Transesophageal Doppler cardiac output monitoring: performance during aortic reconstructive surgery. Anesth Analg 1991; 73: 705-10.

14 Penny JA, Anthony J, Shennan AH, de Swiet M, Singer $M$. A comparison of hemodynamic data derived by pulmonary artery flotation catheter and the esophageal Doppler monitor in preeclampsia. Am J Obstet Gynecol 2000; 183: 658-61.

15 Lavandier B, Muchada R, Cathignol D. The importance of measuring the diameter of the aorta in peroperative blood flow monitoring. V International Symposium on Biomedical Engineering 1994, Santiago: Spain, 1994: 258-9 (abstract).

16 Bernardin G, Tiger F, Fouché R, Mattéi M. Continuous noninvasive measurement of aortic blood flow in critically ill patients with a new esophageal echo-Doppler system. J Crit Care 1998; 13: 177-83.

17 Singer $M$. Esophageal Doppler monitoring of aortic blood flow: beat-by-beat cardiac output monitoring. Int Anesth Clin 1993: 99-125.

18 Histand MB, Wells MK, Reeves JT, Sodal IE, Adamson HP, Wilson JT. Ultrasonic pulsed Doppler transesophageal measurement of aortic haemodynamics in humans. Ultrasonics 1979; 17: 215-8.

19 Rodriguez RM, Berumen KA. Cardiac output measurement with an esophageal Doppler in critically ill emergency department patients. J Emerg Med 2000; 18: 159-64.

20 Klein G, Emmerich M, Maisch O, Dummler R. Clinical evaluation of non-invasive monitoring aortic blood flow $(\mathrm{ABF})$ by a transesophageal echo-Doppler device. Anesthesiology 1998; 89: A446 (abstract).

21 Lefrant J- $\Upsilon$, Bruelle P, Aya AGM, et al. Training is required to improve the reliability of esophageal Doppler to measure cardiac output in critically ill patients. Intensive Care Med 1998; 24: 347-52.

22 Freund PR. Transesophageal Doppler scanning versus thermodilution during general anesthesia. An initial comparison of cardiac output techniques. Am J Surg 1987; 153: 490-4.

23 Stetz CW, Miller RG, Kelly GE, Raffin TA. Reliability of the thermodilution method in the determination of cardiac output in clinical practice. Am Rev Respir Dis 1982; 126: 1001-4.

24 Bland JM, Altman DG. Statistical methods for assessing agreement between two methods of clinical measurement. Lancet 1986: 307-10.

25 Altman D. Practical Statistics for Medical Research. London, UK: Chapman \& Hall, 1991.

26 Baillard C, Cohen $\Upsilon$, Fosse JP, Karoubi P, Hoang P, Cupa M. Haemodynamic measurements (continuous cardiac output and systemic vascular resistance) in critically ill patients: transesophageal Doppler versus continuous thermodilution. Anaesth Intensive Care 1999; 27: 33-7.

27 Cuschieri J, Rivers E, Caruso J, et al. A comparison of transesophageal Doppler, thermodilution and Fick cardiac output measurements in critically ill patients. Crit Care Med 1998; 26(suppl): A62 (abstract).

28 DiCorte CJ, Latham P, Greilich PE, Cooley MV, Grayburn PA, Jessen ME. Esophageal Doppler monitor determinations of cardiac output and preload during cardiac operations. Ann Thorac Surg 2000; 69: 1782-6.

29 Krishnamurthy B, McMurray TJ, McClean E. The perioperative use of the oesophageal Doppler monitor in patients undergoing coronary artery revascularization. 
Anaesthesia 1997; 52: 624-9.

30 Kumar A, Minagoe S, Thangathurai D, et al. Noninvasive measurement of cardiac output during surgery using a new continuous-wave Doppler esophageal probe. Am J Cardiol 1989; 64: 793-8.

31 Madan AK, UyBarreta VV, Aliabadi-Wable S, et al. Esophageal Doppler ultrasound monitor versus pulmonary artery catheter in the hemodynamic management of critically ill surgical patients. J Trauma 1999; 46: 607-11.

32 Mark JB, Steinbrook RA, Gugino LD, et al. Continuous noninvasive monitoring of cardiac output with esophageal Doppler ultrasound during cardiac surgery. Anesth Analg 1986; 65: 1013-20.

33 Perrino AC Jr, Fleming J, LaMantia KR.

Transesophageal Doppler ultrasonography: evidence for improved cardiac output monitoring. Anesth Analg 1990; 71: 651-7.

34 Schmid ER, Spahn DR, Tornic M. Reliability of a new generation transesophageal Doppler device for cardiac output monitoring. Anesth Analg 1993; 77: 971-9.

35 Siegel LC, Shafer SL, Martinez GM, Ream AK, Scott $J C$. Simultaneous measurements of cardiac output by thermodilution, esophageal Doppler, and electrical impedance in anesthetized patients. J Cardiothorac Anesth 1988; 2: 590-5.

36 Singer M, Clarke J, Bennett ED. Continuous hemodynamic monitoring by esophageal Doppler. Crit Care Med 1989; 17: 447-52.

37 Spahn DR, Schmid ER, Tornic M, et al. Noninvasive versus invasive assessment of cardiac output after cardiac surgery: clinical validation. J Cardiothorac Vasc Anesth 1990; 4: 46-59.

38 Stein MS, Barratt SMcG, Purcell GJ. Intraoperative assessment of the Lawrence 3000 Doppler cardiac output monitor. Anaesth Intensive Care 1991; 19: 251-5.

39 Valtier B, Cholley BP, Belot J-P, de la Coussaye J-E, Mateo J, Payen DM. Noninvasive monitoring of cardiac output in critically ill patients using transesophageal Doppler. Am J Respir Crit Care Med 1998; 158: 77-83.

40 Wagner G, Kalckhoff A, Emmerich M, Westhof FB, Klein $G$. Noninvasive monitoring cardiac output (CO) during off-pump coronary artery bypass grafting (OPCABG). New York Post Graduate Assembly. New York: 1999: 115 (abstract).

41 Cariou A, Monchi $M$, Joly $L-M$, et al. Noninvasive cardiac output monitoring by aortic blood flow determination: evaluation of the Sometec Dynemo-3000 system. Crit Care Med 1998; 26: 2066-72.

42 Muchada R, Cathignol D, Lavandier B, Lamazou J, Haro D. Aortic blood flow measurement. Am J Noninvas Cardiol 1988; 2: 24-31.
43 Lavandier B, Cathignol D, Muchada R, Xuan BB, Motin J. Noninvasive aortic blood flow measurement using an intraesophageal probe. Ultrasound Med Biol 1985; 11: 451-60.

44 Lefrant JY, Aya G, de la Coussaye JE, et al. Comparison of cardiac output measured by esophageal Doppler vs thermodilution. Intensive Care Med 1992; 18(suppl 2): $S 177$ (abstract).

45 Raper R, Sibbald WJ. Misled by the wedge? The SwanGanz catheter and left ventricular preload. Chest 1986; 89: 427-34.

46 Calvin JE, Driedger AA, Sibbald WJ. Does the pulmonary capillary wedge pressure predict left ventricular preload in critically ill patients? Crit Care Med 1981; 9: 437-43.

47 Singer M, Bennett ED. Noninvasive optimization of left ventricular filling using esophageal Doppler. Crit Care Med 1991; 19: 1132-7.

48 Mythen $M G$, Webb AR. Perioperative plasma volume expansion reduces the incidence of gut mucosal hypoperfusion during cardiac surgery. Arch Surg 1995; 130: 423-9.

49 Sinclair $S$, James $S$, Singer $M$. Intraoperative intravascular volume optimisation and length of hospital stay after repair of proximal femoral fracture: randomised controlled trial. BMJ 1997; 315: 909-12. 